\section{The role of endoscopy in childhood chronic abdomi- nal pain}

To the Editor: Chronic abdominal pain (CAP) is a common complaint of children presenting to pediatricians and gastroenterologists. It is believed to account for $2 \%$ to $4 \%$ of general pediatric office visits. ${ }^{1}$ Although much is published in the world literature, information about CAP in our community is scarce. Therefore, we report our experience on the value of endoscopy in the investigation of this condition. Between 1993 to 2002, 192 Saudi children were consecutively referred for endoscopy as part of the investigation of CAP. The male-to-female ratio was $0.36: 1$ and the age range was between 2.5 to 18 years. Although the chief complaint of the children was CAP, associated symptoms included vomiting, weight loss, diarrhea, and constipation in decreasing frequency. The pattern of identified conditions is depicted in the table, indicating a diagnosis of organic disease in $97 / 192$ (50.5\%) of the children. These included peptic esophagitis, gastritis, gastroduodenitis, peptic ulcer disease, and inflammatory bowel diseases. The final diagnosis in the remaining 95 children (49.5\%) was functional CAP. $H$. pylori status was available in 75 histopathology reports, and was positive in 35 (46.7\%). Specific therapy was prescribed to patients with organic disease and 60/97 (62\%) improved during a follow-up period ranging from 10 days to 10 years with a median of 6 months.

The terminology of abdominal pain has evolved over the last several decades. At present, it is generally agreed that the original definition of Apley in 1958 is a description rather than a diagnosis; therefore, the Rome II criteria for abdominal pain were developed to help clinicians in the diagnosis. ${ }^{2}$ Even Rome II criteria have not achieved worldwide acceptance, and some clinicians consider abdominal pain to be chronic with shorter duration. ${ }^{3}$ At the primary care level, CAP is usually functional, but in selected children referred to gastroenterologists, the proportion of organic causes is higher. Although the present study is retrospective and therefore has drawbacks, it does document the yield of endoscopy and the pattern of conditions causing CAP in children attending our institution. Despite the fact that only children with significant endoscopic findings were included and therefore cases with erythema of questionable clinical significance were excluded, the finding of $50.5 \%$ esophagogastrointestinal (EGI) diseases is lower than in a study from a semi-private hospital in the Kingdom, ${ }^{4}$ which reported endoscopic findings in $69 \%$ of the children. However, they included all findings, even mild erythema. ${ }^{4}$ However, our results are slightly lower than in a study from Finland reporting pathology in $58.5 \%$ in a group of 82 children complaining of recurrent abdominal pain and associated symptoms for at least 3 months, ${ }^{5}$ but much higher than results in a report from the USA, indicating about $30 \%$ organic causes in a group of 356 children referred

\section{Mohammad El Mouzan \\ Asaad Assiri

\author{
Correspondence: \\ Prof Mohammad El Mouzan \\ King Saud University \\ P.O.Box 2925, Riyadh 11461 \\ Saudi Arabia \\ T: +966 $1467-0807$ \\ F: $+9661467-9463$ \\ drmouzan@gmail.com
}

\section{References}

1. Starfield B, Hoeckelman R, Mc Cormick M, Benson B, Mendenhall RC, Moynihan C, et al. Who provides care to children and adolescents in the United States? Pediatrics 1984; 74: 991-997.

2. Rasquin-Weber A, Hayman PE, Cucchiara $S$ Fleisher DR, Hyams JS, Milla PJ, et al. Childhood functional gastrointestinal disorders. GUT 1999; 45 suppl 2: 1160-1168.

3. American Academy of Pediatrics Subcommittee and NASPGHAN Committee on Chronic Abdominal Pain.J Pediatr Gastroenterol Nutr 2005; 40: 249-

Table 1. Causes of chronic abdominal pain in 97 children.

\begin{tabular}{|c|c|c|c|}
\hline Causes & Number & M/F ratio & $\begin{array}{c}\text { Average age } \\
\text { (yrs) }\end{array}$ \\
\hline Esophagitis & 19 & $1: 0.58$ & 12.5 \\
\hline Gastritis & 30 & $0.28: 1$ & 14.5 \\
\hline Gastroduodenitis & 30 & $0.42: 1$ & 13.7 \\
\hline Peptic ulcer disease* & 9 & 1: 0.78 & 16 \\
\hline Inflammatory bowel disease ${ }^{* *}$ & 9 & $0.2: 1$ & 14.6 \\
\hline
\end{tabular}

- 8 duodenal and one gastric ulcer.

* 8 Crohn disease and one ulcerative colitis. 
261.

4. Edreesi MH. The yield of endoscopy in chronic abdominal pain. Abstract book, p 100. The Ilnd International Symposium on Pediatric Gastroenterology Hepatology and Nutrition. 13-15 January 2003, KFSH\&RC, Riyadh, Saudi Arabia.

5. Ashorn M, Maki M, Ruuska T, Karikoski-Leo R, Halstrom M, Kokki $M$, et al. Upper gastrointestinal endoscopy in recurrent abdominal pain of childhood. J Pediatr Gastroenterol Nutr 1993; 16: 273-277.

6. Croffie JM, Fitzgerald JF, Chong SK. Recurrent abdominal pain in children- a retrospective study of outcome in a group referred to a pediatric gastroenterology practice. Clin Pediatr (Phila) 2000; 39:267-274.

7. Quak SH, Wee A, Quah TC, Quek SC, Lam SK. Helicobacter pylori infection in children with recurrent abdominal pain. Ann Trop Paediatr 1994; 14: $267-270$.

\section{A case of urinary bladder benign polyp treated suc- cessfully by resection in a child}

To the Editor: We report a case of a 3-year old boy that presented with recurrent urine retention secondary to a bladder polyp. Acute urine retention is not common in children. It may be secondary to dysuria whether from urinary tract infection, vaginitis, meatal ulcer, severe constipation with fecal masses compressing the bladder neck, voiding dysfunction, or from medications such as sympathomimetics. ${ }^{1}$ Urethral obstructive lesions such as valves or stones may present with acute urine retention. Bladder polyps, however, are a very rare cause of acute urine retention in children.

The boy was admitted to the Jordan University Hospital with recurrent acute urine retention and painless gross hematuria of 1 -weeks duration. There was a history of urinary frequency, urgency, and suprapubic pain of 2 weeks duration. There was no history of a urine catheter. Physical examination was noncontributory. Urine analysis and culture were negative. A 24-hour urine collection revealed hyperoxaluria. A renal ultrasound was nega- tive.

The patient underwent urethrocystoscopy. There was a mobile greenish soft polypoid pedunculated mass measuring $1.2 \times 0.6 \times 0.5$ $\mathrm{cm}$ in the bladder dome that was resected. Histopathology revealed an infarcted polyp with polypoid fibrovascular tissue lined by a transitional epithelium lacking nuclear atypia. The stroma was edematous and congested with scanty inflammatory cell infiltrates. There was no evidence of malignancy. The patient had one recurrence of the gross hematuria without recurrence of the polyp as demonstrated on repeat cystoscopy. He was put on pyridoxine for the hyperoxaluria.

Recurrent urine retention in children may result from a variety of causes. However, bladder polyps as a cause are rare. Genitourinary tract polyps can occur anywhere from the renal pelvis to the urethra. ${ }^{2-5}$ Bladder polyps are rare in both adults and children. They may present with gross hematuria, voiding dysfunction, ${ }^{6}$ or urine infection..$^{7.10}$ One should always keep in mind malignant tumours such as rhabdomyosarcoma, which may present in a similar manner. Diagnosis is by histopathology. Polyps are usually benign and do not turn malignant or recur. $\mathrm{Al}$ Ahmadie and colleagues reported a giant fibroepithelial polyp in a 3 year old child. ${ }^{11}$ In our patient, the location of the polyp allowed it to act as an intermittent valve, leading to urine retention alternating with symptom-free periods.

The pathogenesis of bladder genitourinary polyps remains to be elucidated. One hypothesis suggests that stone-initiated chronic irritation of the genitourinary mucosa leads to polyp formation. ${ }^{5}$ The role of the stone and crystalluria in the initiation of the localized inflammatory trigger seems appealing.
Murshidi proposed that chronic localized lamina propria edema may cause a mucosal bulge which culminates into a polyp, ${ }^{5}$ but this does not explain the presence of congenital polyps. In our patient, the chronic mucosal irritation with oxalate crystal may have contributed to localized edema and polyp formation.

\section{Mujalli S. Murshidi \\ Kamal Akl}

Correspondence:

Dr. Muhalli S. Murshid

Department of Urology

Jordan University Hospital

P.O. Box 13245

Amman 11942, Jordan

mujalli_mhailan@hotmail.com

\section{References}

1. Gatti JM, Perez- Brayfield M, Kirsch AJ et al. Acute urinary retention in children. Urology 2001 March; 165: 918-921

2 Aita GA, Begliomini H, Mattos D Jr. Fibroepithelial polyp of the urethra. Int Braz J Urol 2005 MarApr, 31(2): 155-6

3. Beluffi, Berton $F$, Gola $G$ et al. Urethral polyp in a 1 month old child. Pediatr Radiol 2005 Jul; 35 (7): $691-3$.

4. Murshidi MS. Fibroepithelial polyp of renal pelvis: Literature review and case report Dirasat. 1985 (oct) XII ( 10): 163-69

5. Murshidi MS. Calculous disease and its relationship to fibroepithelial polyps of the renal pelvis and ureter. Acta Urol Belg 1988; 56 (1 ): 47-54.

6. Gleason E, Kramer SA, Genitourinary polyps in children. Urology 1994 Jul; 44 (1): 106-109

7. Defoor W, Minevich E, Sheldon C. Unusual bladder masses in children Urology. 2002 Nov; 60 (5): 911.

8. Waisman SS, Banko J, Cromie WJ. Single polypoid cystitis cystica and glandularis presenting as benign bladder tumour. Urology .1990 0ct 36 (4): $364-6$.

9. Tsuzuki T, Epstein JI. Fibroepithelial polyp of the lower urinary tract in adults Am J Surg Pathol 2005 Apr, 29 (4): 460-6.

10. Fathi K, Azmy A, Howatson A, et al. Congenital posterior urethral polyps in childhood. A case report. Eur J Pediatr Surg 2004 Jun; 14(3): 215-7

11. Al Ahmadie H, Gomez AM, Trane N et al. Giant botryoid fibroepithelial polyp of the bladder with myofibroblastic stroma and cystitis cystica et glandularis. Pediatr Dev Pathol 2003 Mar-Apr; 6(2): 179-81.

12. Dalens B, Vanneuville G, Vincent L, et al. Congenital polyp of the posterior urethra and vesical calculus in a boy. J Urol 1982; 128 (5): 1034-5. 